INTERACTIVE ARTICLE COVER

RUPKATHA JOURNAL

About the Journal

\begin{tabular}{|c|c|}
\hline \multicolumn{2}{|r|}{ About the Journal } \\
\hline Journal DOI & https://doi.org/10.21659/rupkatha \\
\hline Journal Home & www.rupkatha.com $\triangle$ \\
\hline Indexed by & Scopus $₫$ Web of Science: Emerging Sources Citation Index (ESCI) DOAJ \\
\hline Journal Metrics & CiteScore 2020: 0.2 | SJR 2020: 0.162 | SNIP 2020: 0.193 | JCI 2020: 0.50 \\
\hline \multicolumn{2}{|r|}{ About the Issue } \\
\hline Themed issue & $\begin{array}{l}\text { Volume 4, number 1, } 2022 \text { (January-March) | Contemporary East and } \\
\text { Southeast Asian Literary and Cultural Studies }\end{array}$ \\
\hline Guest Editors & Dr Jeremy de Chavez $\triangle$ \& Dr Zhang Yue, University of Macau, China \\
\hline Issue DOI & https://doi.org/10.21659/rupkatha.v14n1 \\
\hline TOC & https://rupkatha.com/v14n1.php $\square$ \\
\hline Peer Review & Under the responsibility of the Guest Editors \\
\hline \multicolumn{2}{|r|}{ About the Review } \\
\hline Title & $\begin{array}{l}\text { Digital Humanities: Knowledge and Critique in a Digital Age by David M. } \\
\text { Berry and Anders Fagerjord }\end{array}$ \\
\hline Author/s & Xi Li \& Jie Zeng* $\otimes \mid *$ Corresponding author \\
\hline Affiliation & Chungdu Normal University, Sichuan Province, China \\
\hline Funding & Not applicable \\
\hline Article DOI & https://doi.org/10.21659/rupkatha.v14n1.24 Pages: 1-3 \\
\hline Abstract & https://rupkatha.com/v14n124 Ø \\
\hline Full-text PDF & https://rupkatha.com/V14/n1/v14n124.pdf $\oslash$ \\
\hline \multirow[t]{3}{*}{ Article History } & Complete review received: 27 Feb 2021 | Revised review received: 29 Mar 2021 \\
\hline & 2nd round revision: 11 Dec 2021 | Accepted: 12 Dec 2021 \\
\hline & First Published: 05 February 2022 \\
\hline Review Impact & Check Dynamic Impact \\
\hline Copyright & Aesthetics Media Services $\square$ \\
\hline Licensing & Creative Commons Attribution Non-Commercial 4.0 \\
\hline
\end{tabular}

This review is published under a Creative Commons Attribution Non-Commercial 4.0 International License (http://creativecommons.org/licenses/by-nc/4.0/), which permits non-commercial re-use, distribution, and reproduction in any medium, provided the original work is properly cited. For citation use the DOI. For commercial re-use, please contact editor@rupkatha.com. 
1 | Rupkatha Journal, Vol. 14, No. 1, 2022

Book Review

\title{
Digital Humanities: Knowledge and Critique in a Digital Age by David M. Berry and Anders Fagerjord
}

\author{
Publisher: Polity Press \\ Date of Publication: 2017 \\ Language: English \\ ISBN: 9780745697659 \\ Reviewed by \\ Xi Li \& Jie Zeng (corresponding author) \\ Chungdu Normal University, Sichuan Province, China
}

It is no doubt that we are living in an increasingly digitalized world. Seemingly ubiquitous, digitalization has significantly influenced our way of life and thinking. The rapid development and widespread application of digital technology has also stimulated the growth of scholarship. Amongst them, digital humanities is a relatively new discipline that lies at the intersection of computer technology and the humanities. By applying digital tools and technology to the traditional discipline of the humanities, digital humanities is an interdisciplinary and even transdisciplinary field that aims to advance our understanding of humanities as well as digital technology.

Digital Humanities: Knowledge and Critique in a Digital Age by David M. Berry and Anders Fagerjord is another work that joins the academic exploration of this nascent discipline. This slender and massively sourced volume outlines the history, eruptions, and epistemic contexts in which this burgeoning field has sprung. Berry and Anders point out that the digital humanities give us powerful theories, methods and tools for exploring new ways of being in a digital age. They provide a compelling guide by exploring the history, intellectual work, key arguments, and ideas of this emerging discipline. They also offer an important critique, suggesting ways in which the humanities can be enriched through computing as well as how cultural critique can transform the digital humanities.

Drawing on research in the fields of media and communications, digital media, sociology, informatics, and the humanities more broadly, this volume starts with an introductory chapter that offers an overview of this book. Barry and Fagerjord then take readers on an impressive voyage of the history, development, ways of thinking, infrastructures, methods, tools, and critical thinking of digital humanities. In chapter two "Genealogies of the Digital Humanities," the authors delineate the origin, history, and development of this discipline. They also acknowledgement the contradictions and contentions, and multiple definitions that surrounds this discipline. Chapter 3 and chapter 4 examine the epistemology of digital humanities. In Chapter 3 "Computational Thinking," fully aware of the interdisciplinary nature of digital humanities, the authors provide an 
example that attests to such nature rather than simply offering the algorithms. They also acknowledge the constructive role of programming language while pointing out that other approaches to humanities are also welcome. Following the discussion of algorithms, Chapter 4, titled "Knowledge Representation and Archives," offers a quick view of the questions brought by and the practices related to the representation of knowledge. The fifth Chapter "Research Infrastructures" examines the significance of research infrastructures in supporting digital humanities and the conditions of possibility for widening humanities scholarship. The authors call for thinking about research infrastructure not only as material to be stored and preserved but also as a process that helps the transformation of primary sources and the generation of new forms of scholarship. Also, throughout this chapter, the authors suggest that research infrastructure not only exist in physical forms - libraries, labs, research centers-but also in virtual, hybrid forms, thus acknowledging the multi-dimension and development of research infrastructure. As the chapter title "Digital Methods and Tools" suggests, Chapter 6 focuses on the specific methods and approaches that are used to collect digital data in the discipline. The authors also argue that the scope of digital methods can be broadened by incorporating other approaches, such as software studies and the study of works that are not digitized but created digitally. The seventh chapter "Digital Scholarship and Interface Criticism" looks into the question of the interface from a broad perspective, thinking about how to display, publish the results of digital humanities research. Supported by several examples, the authors contend that the understanding of the concept of the interface should go beyond simplistic thinking. Threading all the intersecting concerns in previous chapters, the final chapter "Towards a Critical Digital Humanities" summarizes the possible future directions for the digital humanities by relating it to the notion of critical digital humanities and the social, cultural, economic and political questions of recontextualization of the digital humanities in a social field. Raising a set of questions, this chapter emphasizes again and expands the scope for critical reflexivity.

The strength of this book lies in its sustained call for critical and dialectical thinking in understanding digital humanities. The field has been criticized for privileging techniques, such as technical tools and methods while neglecting the more traditional humanistic perspective. Throughout the volume, the authors have demonstrated a clear awareness of the hybrid or interdisciplinary nature of this discipline and always urge the importance of broadening the understanding and scope of digital humanities. Overall, Digital Humanities effectively demonstrates the computational way of doing humanities research. This volume has documented how digital humanities has grown and developed, mapped its challenges, and proposed new approaches of reconfiguring research and teaching to safeguard critical and rational thought in a digital age. In so doing, this book serves as a helpful guide for anyone who wants to have a basic understanding of digital humanities. Of course, the questions it raises and the suggestions it offers are also generative for future research. 


\section{Acknowledgement}

Foundation Project: The general project of Sichuan Education Informatization Application and Development Research Center "Neuroscience Research on Brain-like Intelligence and Foreign Language Education" (JYXX21-008)

\section{References}

Berry, David M., and Anders Fagerjord. (2017). Digital Humanities: Knowledge and Critique in a Digital Age. John Wiley \& Sons.

$\mathrm{Xi}$ Li is a PhD candidate at the School of English Studies, Sichuan International Studies University and an associate professor at the School of Foreign Languages, Chengdu Normal University.

Jie Zeng is an Associate Professor at the School of Foreign Languages, Chengdu Normal University. Both of them are interested in digital humanities. 